\title{
FLUXOS POLARES E O RITMO DOS SISTEMAS ATMOSFÉRICOS NO NORDESTE DO ESTA- DO DE SÃO PAULO
}

\author{
Polar outflows and the rhythm of atmospheric systems in the northeast of São Paulo State
}

\author{
Gustavo Armani \\ Doutor e Pesquisador Científico do \\ Instituto Geológico/Secretaria do Meio Ambiente - SP \\ São Paulo/SP - Brasil \\ gustavo@igeologico.sp.gov.br \\ Emerson Galvani \\ Professor, Doutor da Universidade de São Paulo - SP \\ São Paulo/SP - Brasil \\ egalvani@usp.br
}

Artigo recebido para publicação em 31/01/2011 e aceito para publicação em 19/04/2011

RESUMO: $\quad$ objetivo deste trabalho foi caracterizar o ritmo dos sistemas atmosféricos no nordeste do estado de São Paulo, a partir da frequência dos sistemas atmosféricos e dos tipos de fluxos polares, entre o inverno de 2008 ao outono de 2009. A análise da circulação foi realizada diariamente por meio da análise sinótica de três niveis isobáricos: superficie, 500 e $250 \mathrm{hPa}$. Os resultados revelaram que houve 45 passagens frontais com duração mais frequente de um dia, controlando 21,9\% do ano. Os intervalos mais frequentes, entre uma frente e outra, foram de 5 a 6 dias, oscilando entre um mínimo de 0 (com duas frentes num mesmo dia) a 18 dias. Os sistemas extratropicais controlaram a maior parte do tempo (64,9\% do ano), sendo que os anticiclônicos atuaram durante 43\% do ano e os frontais, 21,9\%. O restante do tempo foi dominado pelos sistemas tropicais (Atlântico e Continental) (35,1\%), sendo que, desses, o sistema Atlântico atuou por 31,8\% e o Continental, 3,3\%. No periodo, predominaram fluxos polares do tipo oscilante (com uma tendência para interrompido) devido à elevada frequência de sistemas extratropicais (64,9\%), sendo um ano diferente do habitual para este trecho do estado, em que os sistemas tropicais apresentam equivalência no domínio do tempo com os extratropicais (50\% para os tropicais e 50\% para os extratropicais).

Palavras-Chave: São Paulo. Circulação atmosférica. Frequência.

ABSTRACT: The aim of this study was to characterize the rhythm of atmospheric systems in the northeast of São Paulo State, Brazil from the frequency of weather systems and types of polar outflows from the winter of 2008 to the fall of 2009. The circulation analysis was performed by the means of daily synoptic analysis of three isobaric levels: surface, 500 and $250 \mathrm{hPa}$. The results showed that there were 45 frontal passages mostly during one day, controlling $21.9 \%$ of the year. The most frequent intervals between two fronts were of 5 to 6 days, ranging from a minimum of 0 (with two fronts in the same day) to 18 days. Extratropical systems controlled most of the time (64.9\% of year), with the anticyclonic systems acting in $43 \%$ of the year and the frontal ones, in 21.9\%. The remaining time was controlled by tropical (Atlantic and Continental) systems (35.1\%), being 31.8\% by the Atlantic system and 3.3\% by the Continental one. The period was dominated by oscillatory-type polar outflows (tending to interrupted) because of the high 
frequency of extratropical systems (64.9\%), being a different year than the usual for this part of the state, where tropical and extratropical systems control equivalent periods of the year $(50 \%$ for tropical and $50 \%$ for extratropical).

Keywords: São Paulo State. Atmospheric circulation. Frequency.

\section{INTRODUÇÃO}

O ritmo é a essência geográfica do clima (MONTEIRO, 1969). A maioria dos trabalhos em climatologia, comumente, fundamentavam-se no ritmo dos elementos climáticos. Para Azevedo (2001), o ritmo sempre foi o paradigma da climatologia. Assim, por exemplo, Hann e Köppen buscavam, por meio das normais e médias, os ritmos diários e anual da insolação.

Mas foram as proposições de Sorre (1951) e Monteiro $(1963,1968,1969,1971)$ que representaram um avanço ao que era praticado em climatologia, principalmente porque procuraram tratar dos processos interativos entre a atmosfera com o restante do espaço geográfico. O conceito de clima de Sorre (1951, p.13-14), "l'ambience atmosphérique constituée par la série des états de l'atmosfère au-dessus d'un lieu dans leur succession habituelle", coloca novos paradigmas para a interpretação da realidade climática. O conceito de "habitual" é certamente melhor que o uso da média, porque tem, em si, a ideia de retorno, frequência e intensidade, que faz com que se aproxime da noção de ritmo. Outro conceito fundamental é o de "sucessão", que contém as ideias de encadeamento, de duração, de presença-ausência, ou seja, a essência do ritmo (TARIFA, 2002).

Monteiro (1971), apoiado nas ideias de Sorre (1951), propôs a análise rítmica como um processo interativo entre a circulação atmosférica e os elementos do clima. Monteiro (1971, p.9;12-13) estabelece três regras básicas, a saber:

Admitimos, pois, como válida a conclusão de que o ritmo climático só poderá ser compreendido através da representação concomitante dos elementos fundamentais do clima em unidades de tempo cronológicas pelo menos diárias [...]
Só a análise rítmica detalhada ao nível de 'tempo', revelando a gênese dos fenômenos climáticos pela interação dos elementos e fatores dentro de uma realidade regional é capaz de oferecer parâmetros válidos à consideração dos diferentes e variados problemas geográficos [...]

$\mathrm{Na}$ análise rítmica, as expressões quantitativas dos elementos climáticos estão indissoluvelmente ligadas à gênese ou qualidade dos mesmos [...].

A sucessão dos tipos de tempo se manifesta segundo os mecanismos da circulação atmosférica regional. A relação de causalidade da circulação atmosférica (alternância, sucessão, encadeamento) no ritmo climático foi explicitada em vários trabalhos que se iniciaram no Brasil, a partir da década de 1960 (entre outros: ARMANI, 2004, 2009; BOIN; ZAVATTINI, 2005; CONTI, 1975; HAMILTON; TARIFA, 1978; JARDIM, 2001; MONTEIRO, 1969, 1971, 1973; MONTEIRO; TARIFA, 1977; MONTEIRO et al., 1971; RIBEIRO, 1975; SETTE, 1996, 2000; TARIFA, 1973, 1975, 1981, 2002; TARIFA; MONTEIRO, 1972; ZAVATINI, 1992).

As análises da circulação atmosférica no Brasil iniciaram de forma consistente com os trabalhos de Serra (1948, 1954, 1960) e Serra e Ratisbona (1942), os quais, depois, foram adaptados e extensamente utilizados por Monteiro (1963, 1969, 1973) e seguidores a caracterizar a circulação e compreender o ritmo dos sistemas atmosféricos e o ritmo dos elementos climáticos. A maioria dos estudos recentes realiza apenas a relação de causalidade do sistema atmosférico com o ritmo dos elementos climáticos, sendo raros os trabalhos que discutam a frequência, sequência, duração e encadeamento (ritmo) dos sistemas atmosféricos. Quanto ao estado de São Paulo, raros foram os estudos que realizaram este tipo de análise para os sistemas 
atmosféricos, dentre os quais, destacam-se Monteiro (1973), Conti (1975), Tarifa $(1973,1975,2002)$ e Armani (2009).

Neste sentido, os objetivos deste trabalho são: a) caracterizar o ritmo dos sistemas atmosféricos no N.E. do estado de São Paulo, assim, buscando: b) quantificar a frequência dos sistemas atmosféricos com base na análise sinótica de três níveis isobáricos: superfície, 500 e $250 \mathrm{hPa}$; e c) classificar os tipos de fluxos polares neste trecho do estado de São Paulo durante o inverno de 2008 ao outono de 2009. O entendimento dos fluxos polares, conforme sugeriu Monteiro (1969), revela sucintamente a sequência, o encadeamento e a duração dos sistemas atmosféricos entre uma frente polar e outra.

\section{MATERIAIS E MÉTODOS}

A análise da circulação nos três níveis isobáricos (superfície, 500 e $250 \mathrm{hPa}$ ) sobre a área de estudo, no período compreendido entre o inverno de 2008 ao outono de 2009, foi efetuada a partir da análise comparativa das cartas sinóticas elaboradas por: Serviço Meteorológico da Marinha do Brasil (00Z e $12 \mathrm{Z}$ - superfície; <https://www.mar.mil.br/dhn/chm/ meteo/prev/cartas/cartas.htm>), do Centro de Previsão do Tempo e Estudos Climáticos (CPTEC/INPE) (00Z, 06Z, 12Z, e 18Z - superfície, $500 \mathrm{hPa}$, e 250hPa; $<$ http://tempo.cptec.inpe.br/bol_tecnico.shtml $>$ ), e NOAA National Weather Service (00Z, 06Z, 12Z, e $18 \mathrm{Z}$ - superfície, e altitude; $<$ http://www.hpc.ncep. noaa.gov/international/int12.shtml\#charts $>$ ).

As imagens do satélite meteorológico GOES10 (Geostationary Operational Environmental Satellites) dos canais visível $(0,55-0,75 \mu \mathrm{m})$ e infravermelho-termal $(10,2-11,2 \mu \mathrm{m})$, bem como as imagens compostas, foram utilizadas como referências da realidade para verificar os traçados das cartas sinóticas, detectar inconsistências e balizar a decisão da classificação do sistema atmosférico atuante na área de interesse. Este recurso foi fundamental principalmente quando as análises sinóticas dos três centros meteorológicos consultados divergiam.

Utilizaram-se os diagramas Skew T - Log P das estações de São Paulo (Campo de Marte) e do Rio de Janeiro (Galeão) para caracterizar, ou compreender, a estrutura vertical do sistema atmosférico em relação à espessura das altas migratórias, estabilidade e instabilidade.

A análise da circulação atmosférica foi feita para o nível diário (24 horas), conforme os pressupostos de Monteiro (1971), e, eventualmente, detalhada para cada 6 horas (resolução temporal das cartas sinóticas), quando a sucessão entre os sistemas atmosféricos exigia esse detalhe. Nestes casos, mais complexos, a classificação diária foi feita pelo sistema predominante nas 24 horas. Na descrição da situação sinótica realizada, elaborou-se um comentário referente à sucessão dos sistemas ao longo do dia.

A identificação dos campos de pressão e dos sistemas atmosféricos em superfície seguiu o padrão proposto por Monteiro $(1968,1969,1973)$ e por Tarifa (1973, 1975, 2002). Desta forma, separaram-se os sistemas atmosféricos pela sua gênese (origem tropical ou extratropical) e pelas modificações ocorridas durante suas trajetórias quanto a superfícies continentais ou oceânicas.

Os sistemas extratropicais foram subdivididos em dois grupos: os frontais e os anticiclônicos - os primeiros se referem a todas as fácies da Frente Polar. A evolução deste sistema segue normalmente uma sequência que se inicia com a ondulação e o aprofundamento da baixa polar, sendo acompanhada pelo movimento para $\mathrm{N}$ ou N.E. da convergência frontal. A separação intercelular entre anticiclones polares (em diferentes graus de aquecimento), ou entre o anticiclone polar e o tropical na face oriental do continente sul-americano é o que se convencionou chamar de Frente Polar Atlântica (FPA) (TARIFA, 2002). As FPAs, normalmente, manifestam-se até o nível de 500 $\mathrm{hPa}$, sendo bem definidas na análise de espessura entre superfície e $500 \mathrm{hPa}$. Quando esse sistema somente se manifesta em altitude, o CPTEC o designa como Frente Subtropical. Neste trabalho, não se fez essa distinção, sendo classificado como FPA.

O desenvolvimento deste sistema (FPA) no tempo pode dar origem a sistemas frontais alterados, tais como as Frentes Polares Aquecidas ou Frentes Quentes (FQ) com inversão no sentido de propagação (norte-sul). Pode surgir ainda uma série de perturbações indiretas, entre elas as calhas e instabilidades induzidas normalmente orientadas no sentido sul-norte 
ou perpendiculares à FPA. Este conjunto de fenômenos pré e pós-frontais foram agrupados como Repercussão da Frente Polar Atlântica (R).

$\mathrm{Na}$ literatura, encontra-se a possibilidade de ocorrência do Eixo Reflexo da Frente Polar (RFPA), que foi definida como "a separação entre o ar polar já modificado sobre a parte subtropical da vertente atlântica, proveniente de um avanço anterior 'Polar Velha'e o ar tropical Maritimo" (MONTEIRO, 1968, p. 126).

O segundo grupo dos sistemas extratropicais são aqueles relacionados aos desdobramentos do anticiclone migratório polar. Dependendo do local da anticliclogênese, as características destes anticiclones podem ser muito diversificadas. Assim, fez-se uma separação entre o Sistema Polar Continental (SPC) e o Sistema Polar Atlântico (SPA) quando, no primeiro caso, a anticiclogênese e trajetória principal acontecem sobre o continente; e, no segundo, quando se dá preferencialmente sobre o oceano Atlântico. Quando estes sistemas avançam para latitudes mais baixas, eles sofrem um processo de tropicalização, que dá origem ao Sistema Polar Tropicalizado (SPT). O que diferencia este sistema dos tropicais é a existência de uma zona de convergência frontal entre eles. Quando esta zona de convergência se desfaz (fim da frontólise), este sistema passa a ser classificado como Sistema Tropical Atlântico (STA) ou Sistema Tropical Atlântico Continentalizado (STAC) - dependendo da configuração do Anticiclone Subtropical do Atlantico Sul (ASAS).

Os sistemas tropicais também foram subdivididos em oceânicos e continentais. A Alta (anticiclone) Subtropical do Atlântico Sul (ASAS) pode ser desmembrada em dois subsistemas: o seu centro, frequentemente localizado no Atlântico Sul, entre as latitudes $20^{\circ}$ a $30^{\circ} \mathrm{Sul}$, e entre as longitudes $30^{\circ}$ a $10^{\circ}$ Oeste, foi denominado de Sistema Tropical Atlântico (STA); e, no caso do deslocamento de uma dorsal deste anticiclone sobre o continente sul-americano, ele foi denominado Sistema Tropical Atântico Continentalizado (STAC).

Durante a evolução da Frente Polar, é muito frequente o aprofundamento prévio da Depressão Continental do Chaco (DCC), um sistema tropical desenvolvido sobre o continente. Este sistema está térmica e dinamicamente associado à forma e orientação do macrorrelevo do continente sul-americano (Cordilheira dos Andes e planícies interiores do Chaco). Portanto, é um sistema dinâmico associado principalmente aos movimentos ondulatórios dos ventos de oeste a sotavento da Cordilheira dos Andes. Os ventos de oeste, ao ultrapassarem os Andes, sofrem compressão adiabática, promovendo aquecimento do ar e seu ressecamento, assim, contribuindo para as elevadas temperaturas e "secura" características deste sistema. Sua circulação é ciclônica em superfície e anticiclônica em altitude no verão (Alta da Bolívia). Raramente se forma no inverno, todavia é muito comum, durante a primavera-verão, o Sistema da Depressão Continental do Chaco (DCC) atingir as áreas litorâneas (TARIFA, 2002).

É habitual, durante o verão austral, a ocorrência de uma grande e persistente faixa de nebulosidade orientada no sentido N.O.-S.E., desde o sul da Amazônia até o centro-sul do oceano Atlântico, associada a um escoamento convergente de umidade em superfície. Esse padrão de nebulosidade é decorrente de um escoamento em baixos níveis de N.O. para S.E. em forma de jato e em altos níveis à presença de um escoamento anticiclônico sobre o continente sul-americano e um vórtice ciclônico sobre o N.E. do Brasil. Este sistema meteorológico transfere umidade, calor e momento da Amazônia para o sudeste do Brasil, sendo comumente designado de Zona de Convergência do Atlântico Sul (ZCAS). Muitas vezes, a FPA organiza e intensifica a convecção no Brasil central, contribuindo para a formação da ZCAS.

Com os deslocamentos frontais para latitudes mais baixas, é comum a advecção quente com ventos de N.O. Os fluxos advectivos aquecidos de N.O. foram caracterizados como a atuação do Sistema Tropical Continental (STC). Este sistema pode atuar conjuntamente com a DCC, fato muito comum na primavera-verão. Para efeitos de frequência dos sistemas, considerou-se a atuação deles como um todo (STC/DCC), muito embora eles possam ter atuados isoladamente.

Nos níveis de 500 e 250 hPa, classificaram-se os "centros de ação" em: anticiclone, cavado, vórtice ciclônico (VC), escoamento zonal, escoamento ciclônico, escoamento difluente e Jato Subtropical (JST) 
(somente para o nível de $250 \mathrm{hPa}$ ). A identificação desses sistemas permitiu um aprofundamento no conhecimento das relações de causalidade entre os sistemas de superfície e os de altitude, determinando ou influenciando o tipo de tempo. A transferência de energia da atmosfera de níveis superiores para os inferiores também pode ser explicada, em parte, por esta análise complementar. Às vezes, não se notou nenhuma influência direta ou explícita dos níveis superiores; mas, em outras condições, a influência foi importante para aquilo que acontecia em superfície.

Para sintetizar os resultados se optou por apresentá-los em quadros com a frequência absoluta $\left(\mathrm{n}^{\mathrm{o}}\right.$ de dias) e relativa (\%) de cada sistema para cada mês, cada estação e para o período de um ano considerado entre o inverno de 2008 ao outono de 2009. A frequência relativa foi calculada considerando o número de dias de atuação dos sistemas dividido pelo total de dias da estação. A partir da frequência relativa dos sistemas tropicais e extratropicais entre uma frente e outra e também para as estações do ano, classificou-se o tipo de fluxo polar predominante no período, de acordo com a proposta de Monteiro (1969) e adaptada por Tarifa (1975). Desta forma, atribuiu-se quatro classes para os tipos de fluxo polar:

a) Nulo: quando não há abastecimento polar e não se define o anticiclone migratório polar. É caracterizado pela dominância dos sistemas tropicais na área de estudo.

b) Interrompido: o fluxo polar é constantemente bloqueado pelos sistemas tropicais, com a alta migratória polar e baixos valores isobáricos. Há certo equilíbrio na frequência dos sistemas polares e tropicais.

c) Oscilante: há o predomínio dos sistemas extratropicais em cerca de $70 \%$ do tempo.

d) Dominante: o predomínio dos sistemas extratropicais é maior que $80 \%$.
Uma das premissas para a compreensão do ritmo climático é o detalhamento da atuação dos sistemas frontais. A FPA na costa sul oriental do Brasil é um importante controle climático, pois ela é responsável pela maior parte da pluviosidade (aproximadamente 70\%). Derivados dos processos frontológicos estão, além da chuva, a nebulosidade associada, a mudança nos padrões de escoamento da baixa troposfera e o resfriamento e aquecimento pós e pré-frontal, respectivamente. Além disso, ela é importante como uma referência para o ritmo e para a sequência dos tipos de tempo. A partir dessas premissas, então, foi caracterizado o número de passagens frontais, a duração do sistema sobre a área de estudo (dias), bem como o intervalo entre uma frente e outra (dias). Portanto, foi descrito o padrão de sucessão dos sistemas atmosféricos entre uma frente e outra de modo a caracterizar a sequência e o encadeamento dos sistemas entre uma frente e outra. Na tabela síntese das FPAs, essa sequência foi resumida ou retratada, de certo modo, pelo tipo de fluxo polar.

Considerou-se como duração da FPA o número de dias com tipos de tempo vinculados ao sistema frontal, desde o aquecimento pré-frontal, a repercussão de aproximação dela até as perturbações pós-frontais embebidas na alta migratória polar.

\section{RESULTADOS E DISCUSSÃO}

\section{Inverno 2008}

Os sistemas anticiclônicos (tropicais e extratropicais) controlaram a maior parte do tempo nesta estação ( $83,7 \%$ ou 77 dias). Os sistemas anticiclônicos extratropicais foram os mais atuantes, com 42,4\% (39 dias), seguido pelos tropicais (STA e STAC) $(41,3 \%$ do período). Os outros $16,3 \%$ do período foram controlados pelos sistemas extratropicais frontais (FPA e R) (Quadro 1, Figura 1). 
Fluxos polares e o ritmo dos sistemas atmosféricos no nordeste do estado de São Paulo Gustavo Armani, Emerson Galvani

\begin{tabular}{|c|c|c|c|c|c|c|c|c|c|c|c|c|}
\hline \multirow{2}{*}{\multicolumn{3}{|c|}{ Sistemas }} & \multicolumn{2}{|c|}{ Inverno 08} & \multicolumn{2}{|c|}{ Primavera 08} & \multicolumn{2}{|c|}{ Verão 08/09 } & \multicolumn{2}{|c|}{ Outono 09} & \multicolumn{2}{|c|}{ Ano $2008 / 2009$} \\
\hline & & & $F$ (dias) & $\%$ & $F$ (dias) & $\%$ & $F$ (dias) & $\%$ & $F$ (dias) & $\%$ & $F$ (dias) & $\%$ \\
\hline \multirow{9}{*}{ 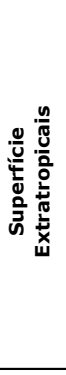 } & \multirow{4}{*}{ 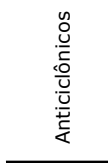 } & SPC & 1,0 & 1,1 & 1,0 & 1,1 & 0,0 & 0,0 & 7,0 & 7,7 & 9,0 & 2,5 \\
\hline & & SPA & 17,0 & 18,5 & 21,0 & 22,8 & 12,0 & 13,3 & 25,0 & 27,5 & 75,0 & 20,5 \\
\hline & & SPT & 21,0 & 22,8 & 19,0 & 20,7 & 11,0 & 12,2 & 22,0 & 24,2 & 73,0 & 20,0 \\
\hline & & Total & 39,0 & 42,4 & 41,0 & 44,6 & 23,0 & 25,6 & 54,0 & 59,3 & 157,0 & 43,0 \\
\hline & \multirow{4}{*}{$\begin{array}{l}\frac{n}{\pi} \\
\stackrel{0}{0} \\
\frac{0}{L}\end{array}$} & FPA & 13,0 & 14,1 & 11,0 & 12,0 & 10,0 & 11,1 & 14,0 & 15,4 & 48,0 & 13,2 \\
\hline & & $\mathrm{FQ}$ & 0,0 & 0,0 & 0,0 & 0,0 & 1,0 & 1,1 & 0,0 & 0,0 & 1,0 & 0,3 \\
\hline & & $R$ & 2,0 & 2,2 & 12,0 & 13,0 & 11,0 & 12,2 & 6,0 & 6,6 & 31,0 & 8,5 \\
\hline & & Total & 15,0 & 16,3 & 23,0 & 25,0 & 22,0 & 24,4 & 20,0 & 22,0 & 80,0 & 21,9 \\
\hline & \multicolumn{2}{|c|}{ Total Geral } & 54,0 & 58,7 & 64,0 & 69,6 & 45,0 & 50,0 & 74,0 & 81,3 & 237,0 & 64,9 \\
\hline \multirow{5}{*}{ 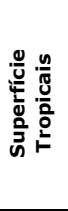 } & \multirow{3}{*}{ Atlântico } & STA & 15,0 & 16,3 & 7,0 & 7,6 & 27,0 & 30,0 & 15,0 & 16,5 & 64,0 & 17,5 \\
\hline & & STAC & 23,0 & 25,0 & 10,0 & 10,9 & 17,0 & 18,9 & 2,0 & 2,2 & 52,0 & 14,2 \\
\hline & & Total & 38,0 & 41,3 & 17,0 & 18,5 & 44,0 & 48,9 & 17,0 & 18,7 & 116,0 & 31,8 \\
\hline & \multicolumn{2}{|c|}{ Continental STC/DCC } & 0,0 & 0,0 & 11,0 & 12,0 & 1,0 & 1,1 & 0,0 & 0,0 & 12,0 & 3,3 \\
\hline & \multicolumn{2}{|c|}{ Total Geral } & 38,0 & 41,3 & 28,0 & 30,4 & 45,0 & 50,0 & 17,0 & 18,7 & 128,0 & 35,1 \\
\hline \multirow{6}{*}{ 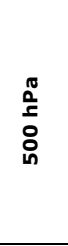 } & \multicolumn{2}{|l|}{ Anticiclone } & 53,0 & 57,6 & 25,0 & 27,2 & 53,0 & 58,9 & 27,0 & 29,7 & 158,0 & 43,3 \\
\hline & \multicolumn{2}{|l|}{ Cavado } & 31,0 & 33,7 & 54,0 & 58,7 & 29,0 & 32,2 & 37,0 & 40,7 & 151,0 & 41,3 \\
\hline & \multicolumn{2}{|l|}{ vc } & 0,0 & 0,0 & 0,0 & 0,0 & 1,0 & 1,1 & 2,0 & 2,2 & 3,0 & 0,8 \\
\hline & \multicolumn{2}{|c|}{ Escoamento zonal } & 6,0 & 6,5 & 6,0 & 6,5 & 4,0 & 4,4 & 13,0 & 14,3 & 29,0 & 7,9 \\
\hline & \multicolumn{2}{|c|}{ Escoamento ciclônico } & 2,0 & 2,2 & 2,0 & 2,2 & 2,0 & 2,2 & 12,0 & 13,2 & 18,0 & 4,9 \\
\hline & \multicolumn{2}{|c|}{ Escoamento difluente } & 0,0 & 0,0 & 5,0 & 5,4 & 1,0 & 1,1 & 0,0 & 0,0 & 6,0 & 1,6 \\
\hline \multirow{8}{*}{ 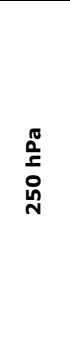 } & \multicolumn{2}{|l|}{ Anticiclone } & 19,0 & 20,7 & 18,0 & 19,6 & 46,0 & 51,1 & 18,0 & 19,8 & 101,0 & 27,8 \\
\hline & \multicolumn{2}{|l|}{ Cavado } & 25,0 & 27,2 & 21,0 & 22,8 & 17,0 & 18,9 & 20,0 & 22,0 & 83,0 & 22,7 \\
\hline & \multicolumn{2}{|l|}{ VC } & 0,0 & 0,0 & 0,0 & 0,0 & 0,0 & 0,0 & 0,0 & 0,0 & 0,0 & 0,0 \\
\hline & \multicolumn{2}{|c|}{ Escoamento Zonal } & 17,0 & 18,5 & 4,0 & 4,3 & 5,0 & 5,6 & 7,0 & 7,7 & 33,0 & 9,0 \\
\hline & \multicolumn{2}{|c|}{ Escoamento Difluente } & 0,0 & 0,0 & 22,0 & 23,9 & 21,0 & 23,3 & 4,0 & 4,4 & 47,0 & 12,9 \\
\hline & \multicolumn{2}{|c|}{$\begin{array}{l}\text { Escoamento } \\
\text { Anticiclônico }\end{array}$} & 1,0 & 1,1 & 1,0 & 1,1 & 0,0 & 0,0 & 2,0 & 2,2 & 4,0 & 1,1 \\
\hline & Escoament & o Ciclônico & 2,0 & 2,2 & 1,0 & 1,1 & 0,0 & 0,0 & 2,0 & 2,2 & 5,0 & 1,4 \\
\hline & JST & & 28,0 & 30,4 & 25,0 & 27,2 & 1,0 & 1,1 & 38,0 & 41,8 & 92,0 & 25,1 \\
\hline
\end{tabular}

Quadro 1: Frequência sazonal dos sistemas atmosféricos no nordeste do estado de São Paulo Org.: Gustavo Armani, verão, 2010.

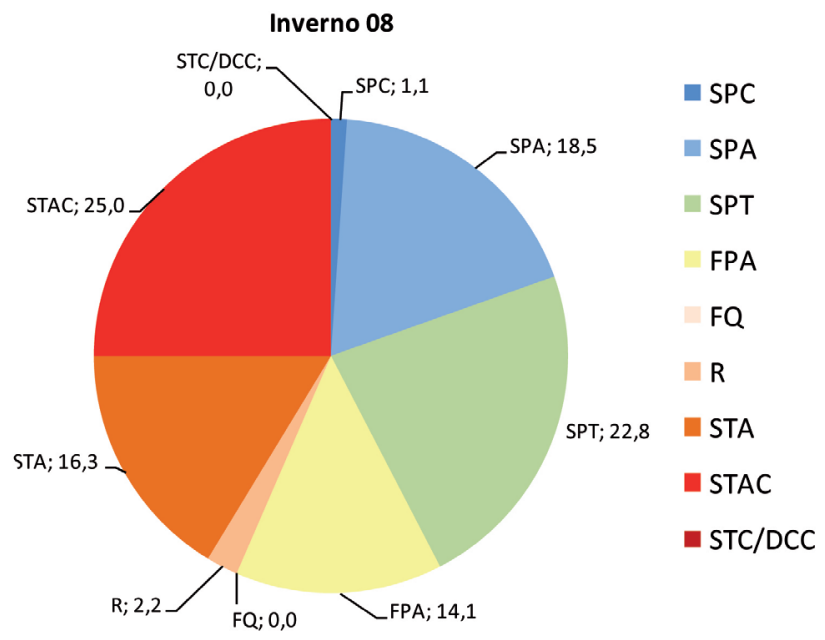

Figura 1: Frequência dos sistemas atmosféricos durante o inverno de 2008, no nordeste do estado de São Paulo Org.: Gustavo Armani, verão, 2010. 
O sistema mais frequente nesta estação foi STAC (25\%), inclusive podendo-se compreender que ele só se forma, ou se define melhor, quando há, nos níveis de 500 e $250 \mathrm{hPa}$, um anticiclone sobre a crista da ASAS que está sobre o continente. Essa superposição de anticiclones favorece a subsidência do ar, promovendo a compressão adiabática do ar e o ressecamento da coluna troposférica, dessa maneira, resultando em menores valores de umidade absoluta, umidade relativa e em temperaturas de ponto de orvalho relativamente menores. Quando essa superposição não era marcante, o sistema em superfície sofria uma modificação, ou para o STA, com o consequente recuo da crista da ASAS para o Atlântico, ou com a entrada do STC, ou mesmo da FPA, com suas repercussões (Quadros 1 e 2).

\begin{tabular}{|c|c|c|c|c|c|c|c|c|c|c|c|c|c|c|c|c|c|c|}
\hline & Sistemas & \begin{tabular}{|l|l|} 
jul/08 \\
\end{tabular} & \begin{tabular}{|l|l|} 
ago/08 \\
\end{tabular} & set/08 & Inverno 08 & out $/ 08$ & nov/08 & dez/08 & Primavera 08 & jan/09 & fev/09 & mar/09 & Verão 08/09 & abr/09 & \begin{tabular}{l|l|} 
mai/09 \\
\end{tabular} & jun/09 & Outono 09 & Ano 2008/2009 \\
\hline \multirow{6}{*}{ 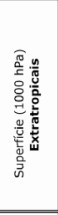 } & SPC & 0,0 & 0,0 & 3,3 & 1,1 & 0,0 & 0,0 & 3,2 & 1,1 & 0,0 & 0,0 & 0,0 & 0,0 & 6,7 & 0,0 & 16,7 & 7,7 & 2,5 \\
\hline & 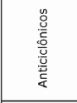 & 12,9 & 12,9 & 30,0 & 18,5 & 16,1 & 33,3 & 19,4 & 22,8 & 19,4 & 0,0 & 19,4 & 13,3 & 26,7 & 25,8 & 30,0 & 27,5 & 20,5 \\
\hline & SPT & 45,2 & 6,5 & 16,7 & 22,8 & 12,9 & 40,0 & 9,7 & 20,7 & 12,9 & 3,6 & 19,4 & 12,2 & 36,7 & 16,1 & 20,0 & 24,2 & 20,0 \\
\hline & \multirow{3}{*}{ de } & 6,5 & 16,1 & 20,0 & 14,1 & 19,4 & 6,7 & 9,7 & 12,0 & 12,9 & 10,7 & 9,7 & 11,1 & 16,7 & 16,1 & 13,3 & 15,4 & 13,2 \\
\hline & & 0,0 & 0,0 & 0,0 & 0,0 & 0,0 & 0,0 & 0,0 & 0,0 & 0,0 & 3,6 & 0,0 & 1,1 & 0,0 & 0,0 & 0,0 & 0,0 & 0,3 \\
\hline & & 3,2 & 0,0 & 3,3 & 2,2 & 9,7 & 3,3 & 25,8 & 13,0 & 16,1 & 14,3 & 6,5 & 12,2 & 3,3 & 9,7 & 6,7 & 6,6 & 8,5 \\
\hline \multirow{3}{*}{ 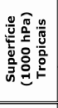 } & \multirow{2}{*}{ Allântico } & 32,3 & 16,1 & 0,0 & 16,3 & 12,9 & 0,0 & 9,7 & 7,6 & 16,1 & 28,6 & 45,2 & 30,0 & 10,0 & 25,8 & 13,3 & 16,5 & 17,5 \\
\hline & & 0,0 & 48,4 & 26,7 & 25,0 & 29,0 & 3,3 & 0,0 & 10,9 & 19,4 & 39,3 & 0,0 & 18,9 & 0,0 & 6,5 & 0,0 & 2,2 & 14,2 \\
\hline & \begin{tabular}{|l|l|} 
Continental STC/DCC \\
\end{tabular} & 0,0 & 0,0 & 0,0 & 0,0 & 0,0 & 13,3 & 22,6 & 12,0 & 3,2 & 0,0 & 0,0 & 1,1 & 0,0 & 0,0 & 0,0 & 0,0 & 3,3 \\
\hline \multirow{6}{*}{ 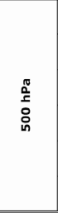 } & Anticiclone & 71,0 & 54,8 & 46,7 & 57,6 & 48,4 & 13,3 & 19,4 & 27,2 & 38,7 & 71,4 & 67,7 & 58,9 & 36,7 & 38,7 & 13,3 & 29,7 & 43,3 \\
\hline & Cavado & 29,0 & 25,8 & 46,7 & 33,7 & 41,9 & 66,7 & 67,7 & 58,7 & 45,2 & 25,0 & 25,8 & 32,2 & 43,3 & 45,2 & 33,3 & 40,7 & 41,4 \\
\hline & vc & 0,0 & 0,0 & 0,0 & 0,0 & 0,0 & 0,0 & 0,0 & 0,0 & 0,0 & 3,6 & 0,0 & 1,1 & 3,3 & 3,2 & 0,0 & 2,2 & 0,8 \\
\hline & Escoamento zonal & 0,0 & 12,9 & 6,7 & 6,5 & 6,5 & 10,0 & 3,2 & 6,5 & 6,5 & 0,0 & 6,5 & 4,4 & 16,7 & 6,5 & 20,0 & 14,3 & 7,9 \\
\hline & Escoamento ciclônico & 0,0 & 6,5 & 0,0 & 2,2 & 0,0 & 3,3 & 3,2 & 2,2 & 6,5 & 0,0 & 0,0 & 2,2 & 0,0 & 6,5 & 33,3 & 13,2 & 4,9 \\
\hline & Escoamento difluente & 0,0 & 0,0 & 0,0 & 0,0 & 3,2 & 6,7 & 6,5 & 5,4 & 3,2 & 0,0 & 0,0 & 1,1 & 0,0 & 0,0 & 0,0 & 0,0 & 1,6 \\
\hline \multirow{8}{*}{ 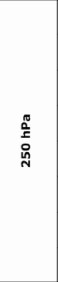 } & Anticiclone & 25,8 & 22,6 & 13,3 & 20,7 & 19,4 & 10,0 & 29,0 & 19,6 & 38,7 & 60,7 & 54,8 & 51,1 & 20,0 & 25,8 & 13,3 & 19,8 & 27,7 \\
\hline & Cavado & 29,0 & 29,0 & 23,3 & 27,2 & 16,1 & 26,7 & 25,8 & 22,8 & 25,8 & 10,7 & 19,4 & 18,9 & 33,3 & 16,1 & 16,7 & 22,0 & 22,7 \\
\hline & vc & 0,0 & 0,0 & 0,0 & 0,0 & 0,0 & 0,0 & 0,0 & 0,0 & 0,0 & 0,0 & 0,0 & 0,0 & 0,0 & 0,0 & 0,0 & 0,0 & 0,0 \\
\hline & Escoamento Zonal & 22,6 & 12,9 & 20,0 & 18,5 & 3,2 & 6,7 & 3,2 & 4,3 & 3,2 & 0,0 & 12,9 & 5,6 & 13,3 & 9,7 & 0,0 & 7,7 & 9,0 \\
\hline & Escoemento Difluente & 0,0 & 0,0 & 0,0 & 0,0 & 41,9 & 16,7 & 12,9 & 23,9 & 29,0 & 28,6 & 12,9 & 23,3 & 0,0 & 12,9 & 0,0 & 4,4 & 12,9 \\
\hline & $\begin{array}{l}\text { Escoamento } \\
\text { Anticiclónico }\end{array}$ & 3,2 & 0,0 & 0,0 & 1,1 & 3,2 & 0,0 & 0,0 & 1,1 & 0,0 & 0,0 & 0,0 & 0,0 & 0,0 & 6,5 & 0,0 & 2,2 & 1,1 \\
\hline & Escoamento Ciclônico & 0,0 & 6,5 & 0,0 & 2,2 & 3,2 & 0,0 & 0,0 & 1,1 & 0,0 & 0,0 & 0,0 & 0,0 & 0,0 & 0,0 & 6,7 & 2,2 & 1,4 \\
\hline & JST & 19,4 & 29,0 & 43,3 & 30,4 & 12,9 & 40,0 & 29,0 & 27,2 & 3,2 & 0,0 & 0,0 & 1,1 & 33,3 & 29,0 & 63,3 & 41,8 & 25,2 \\
\hline
\end{tabular}

Quadro 2: Frequência mensal, sazonal e anual dos sistemas atmosféricos durante o inverno de 2008 ao outono de 2009 , no nordeste do estado de São Paulo

Org.: Gustavo Armani, verão, 2010.

Fonte: Dados da Pesquisa

As FPAs atuaram durante $14,1 \%$ (13 dias), sendo que estacionaram, com frequência, em latitudes mais baixas que a área de estudo, fazendo com que a alta migratória polar se tropicalizasse, dando origem ao SPT e justificando a alta frequência desse sistema no inverno (Quadros 1 e 2). Nesta estação, ocorreram 10 passagens frontais com duração (atuação) mais frequente de um dia. No início da estação, os intervalos entre uma frente e outra eram maiores, próximos de 10 dias (Quadro 3). A média dos intervalos entre uma frente e outra foi de 8,5 dias, mas, como se pode observar, essa média não retrata bem a variação dos intervalos entre uma frente e outra e contradiz a teoria facilmente encontrada na literatura de um intervalo de 7 dias entre uma frente e outra. O maior intervalo registrado nesta estação, entre um avanço frontal e outro, foi de 18 dias; e o menor, de 3 dias. A sequência dos sistemas atmosféricos entre uma frente e outra no inverno seguiu quase o padrão clássico descrito para o estado de SP, ou seja, após a passagem frontal, a alta migratória polar avança sobre o território paulista fazendo o SPA controlar o tempo durante alguns dias; este sistema passa por um processo de tropicalização (SPT), o qual, posteriormente, é embebido pela ASAS, 
passando a dominar o STA ou STAC, sendo, em seguida, substituído por uma nova FPA. Nesta cadeia de sistemas atmosféricos, não foi importante, do ponto de vista da frequência, o aquecimento pré-frontal ca- racterístico antes da entrada da nova frente (STC). O maior tempo de duração de uma frente nesta estação foi de 5 dias, que foi o penúltimo avanço frontal desta estação (Quadro 3).

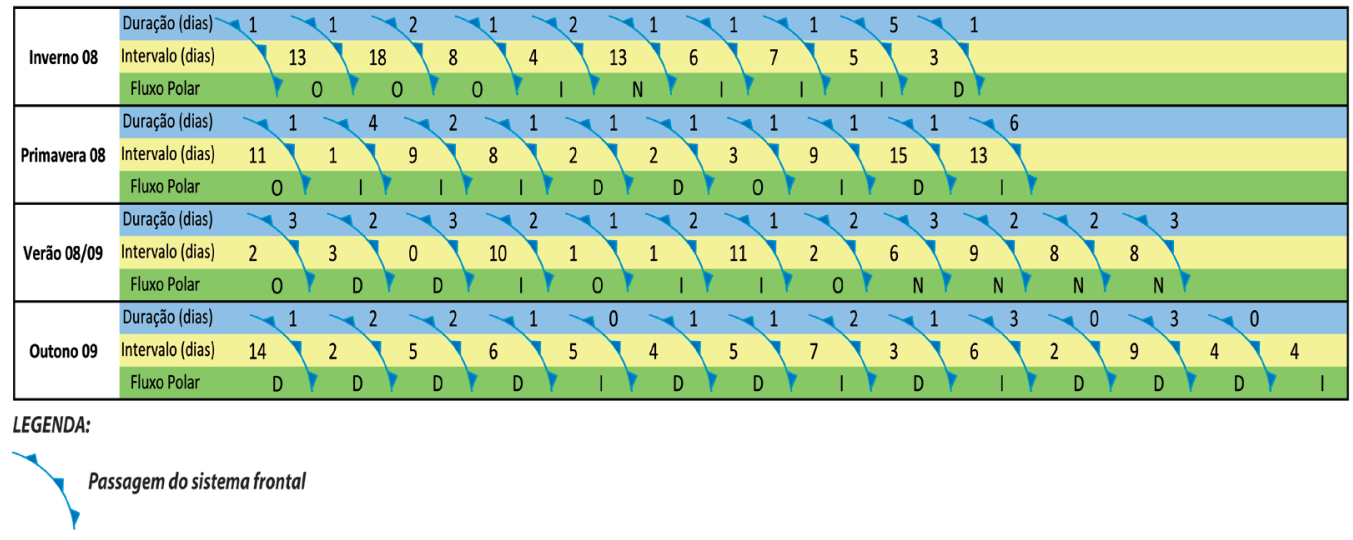

Duração do sistema frontal: inclui o número de dias com tipos de tempo vinculados ao sistema frontal que passou pela área, incluindo o aquecimento préfrontal, a repercussão da aproximação da frente, até as perturbaçōes pós-frontais embebidas na alta migratória polar.

Intervalo entre os sistemas frontais: número de dias entre o sistema frontal e o próximo.

Fluxo Polar: sintetiza a frequencia dos sistemas intertropicais e extra-tropicais.

$\mathbf{N}=\mathbf{N U L O}$ - domínio dos sistemas intertropicais durante mais de $75 \%$ do período.

I = INTERROMPIDO - O fluxo polar é constantemente bloqueado, resultando no equilibrio da frequencia dos sistemas polares e tropicais.

$\mathbf{O}=\mathbf{O S C I L A N T E}$ - os sistemas polares exercem controle predominante, com mais de $75 \%$ do período.

D = DOMINANTE - controle maior ou igual a $85 \%$ do período pelos sistemas extra-tropicais.

Quadro 3: Ritmo sazonal dos sistemas frontais (número, duração e intervalo) e os fluxos polares no nordeste do estado de São Paulo.

Org.: Gustavo Armani, verão, 2010.

A frequência de FPA nos meses de inverno aumentou de julho $(6,5 \%)$ até setembro $(20 \%)$, tendência seguida pelo SPA. Situação inversa a essa aconteceu com os sistemas tropicais, ou seja, a frequência deles diminuiu ao longo do inverno. Essa dinâmica no inverno pode indicar uma lenta mudança de ritmo para primavera (Quadro 3).

A partir da frequência dos sistemas, classificou-se esta estação com um fluxo polar interrompido, ou seja, o fluxo polar foi constantemente bloqueado pelos sistemas tropicais, com a alta migratória polar apontando baixos valores isobáricos. Houve certo equilíbrio na frequência dos sistemas polares e tropicais. De certa forma, o maior intervalo entre as FPAs observado nesta estação, a tropicalização da alta migratória e o domínio do STA ou STAC, constituiu os principais fatores deste tipo de fluxo polar no inverno de 2008. Esse tipo de fluxo polar, nesta estação do ano, é representativo do habitual para o N.E. do estado de São Paulo, de acordo com os resultados apresentados por Monteiro $(1969,1973)$. Entretanto, no início da estação, predominou o fluxo oscilante, sendo que, do segundo terço da estação até o final, a frequência dos sistemas intertropicais aumentou, por conseguinte, fazendo com que os fluxos polares fossem classificados como interrompidos, com apenas uma ocorrência do fluxo polar nulo. O último fluxo polar da estação foi classificado como dominante, cujo período teve uma duração de atuação da FPA de 5 dias (Quadro 3).

De certa forma e respeitando os ajustes feitos neste trabalho para os sistemas atmosféricos, os resultados são concordantes com a situação descrita por Monteiro (1968), quando afirma que, no inverno, o "[...] Brasil Meridional será, consequentemente, afetado pela Massa Tropical Atlântica, de modo mais persistente, à qual vem contrapor-se a Massa Polar Atlântica, mais impetuosa nesta estação, de efeitos mais violentos, mas agindo através de ondas esparsas" (MONTEIRO, 1968, p. 131). 
Em 250 e $500 \mathrm{hPa}$, foi bastante alta a frequência do anticiclone de 250 e $500 \mathrm{hPa}(20,6 \%$ e $56,7 \%$ respectivamente). Estes sistemas e o escoamento zonal garantiram a estabilidade atmosférica desta estação e reforçaram os sistemas estáveis em superfície (Quadros 1 e 2). Ocorreram 4 dias com geadas no Planalto da Bocaina, em julho, que foram favorecidas pela superposição dos anticiclones de altitude com o SPT em superfície, favorecendo a perda noturna de calor devido à baixa umidade e ausência de nebulosidade nestas situações atmosféricas. A posição dos anticiclones de 250 e $500 \mathrm{hPa}$ e em superfície concordam com os resultados apresentados por Serra (1954), Serra e Ratisbona (1942) e Strang (1986).

Aárea baroclínica atinge latitudes mais baixas no inverno, fato que justifica a alta frequência $(30,4 \%)$ do JST sobre a área de estudo. A teoria apresentada por Kousky e Elias (1982), para a posição da baroclínia nesta estação, está de acordo com os resultados encontrados. O suporte dinâmico que as correntes de jato forneceram à FPA em superfície justifica a tendência de aumento relativamente semelhante destes dois sistemas ao longo do inverno (Quadro 2).

\section{Primavera 2008}

A circulação na primavera não se modifica rapidamente em relação àquela observada no inverno. Muito pelo contrário, é possível notar certa continuidade da estação anterior, embora menos nítida e menos intensa, em outubro, sendo que, a partir de novembro, já se nota maiores afinidades com a circulação de verão, fato, também, descrito por Serra e Ratisbona (1942) e Monteiro (1968).

Nesta estação, notou-se uma diminuição da atuação dos sistemas tropicais ( $30,4 \%$ ou 28 dias), mas indicando o início de atuação do STC/DCC (12\% ou 11 dias) devido ao maior aquecimento do continente em relação à estação anterior e ao deslocamento para leste da ASAS. A frequência desses sistemas (STC/ DCC) aumentou progressivamente de outubro ( $0 \%)$ para dezembro (22,6\%) (Quadros 1 e 2; Figura 2), que é um fato esperado nesta estação do ano, conforme assinalado por Serra e Ratisbona (1942) e Monteiro (1968, 1973).

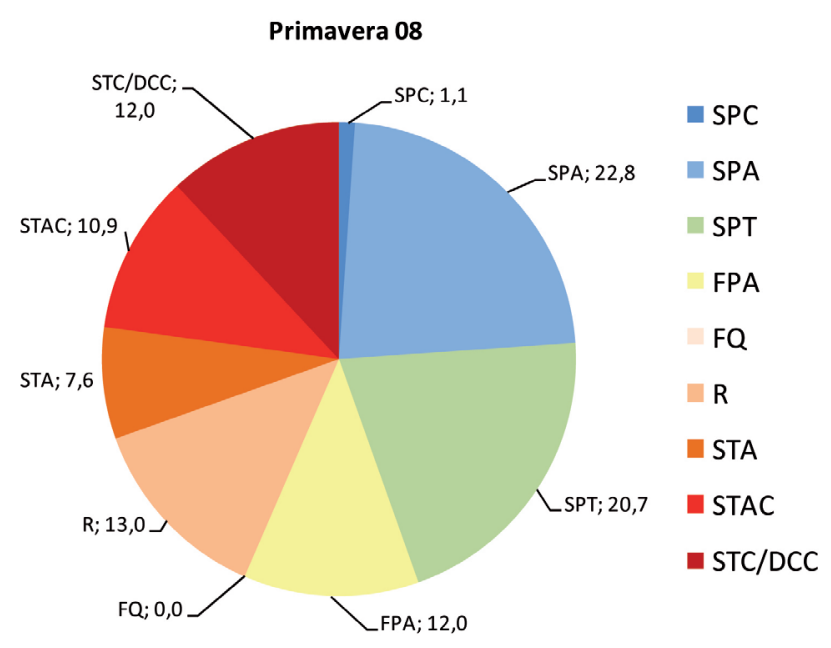

Figura 2: Frequência dos sistemas atmosféricos durante a primavera de 2008, no nordeste do estado de São Paulo. Org.: Gustavo Armani, verão, 2010.

O número de repercussões da FPA (R) aumentou em relação ao inverno em função do aumento de formação de calhas induzidas, favorecidas pela definição da DCC, fatos bem documentados por Serra (1942), Monteiro (1968, 1973) e Tarifa (1975).
Os sistemas de extratropicais foram os predominantes $(69,6 \%$ ou 64 dias), principalmente o SPA (22,8\% ou 21 dias), enquanto o SPC atuou durante apenas 1 dia (Quadros 1 e 2, Figura 2). A FPA atuou durante $12 \%$ da estação e, em $13 \%$, ocorreu alguma 
repercussão dela $(\mathrm{R})$. Essas instabilidades foram favorecidas pelos cavados em 500 e $250 \mathrm{hPa}$, que foram os sistemas mais frequentes. O JST, também, deu suporte dinâmico a algumas passagens da FPA (Quadros 1 e 2). Essa dinâmica da primavera respeita o padrão habitual para o nordeste do estado de São Paulo (MONTEIRO, 1973; TARIFA, 1975).

Ocorreram 10 passagens frontais na primavera, com um intervalo médio entre elas de 7,3 dias. Entretanto, deram-se intervalos de 15 dias e de um dia, sendo que os intervalos mais longos (de 9 a 13 dias) foram os mais frequentes (Quadro 3).

A duração das FPAs mais comum foi de 1 dia (avanços mais rápidos), sendo que houve uma frente que durou 2 dias, outra 4 e a maior duração registrada foi de 6 dias, já na transição para o verão (próximo do solstício de verão). A sucessão dos sistemas entre uma frente e outra também seguiu o padrão clássico de evolução para o estado de São Paulo, tal como no inverno. Após a passagem frontal, a alta migratória polar avança sobre o território paulista fazendo o SPA controlar o tempo durante alguns dias; este sistema passa por um processo de tropicalização (SPT), o qual, posteriormente, é embebido pela ASAS, passando a dominar o STA ou STAC e sendo, em seguida, substituído por uma nova FPA. Entretanto, na segunda metade da primavera, após a tropicalização da alta migratória, ocorreu com maior frequência a atuação dos sistemas tropicais continentais (STC/DCC) (Quadros 2 e 3 ).

Nesta estação, o fluxo polar pôde ser classificado como oscilante, ou seja, ocorreu o predomínio dos sistemas extratropicais em cerca de $70 \%$ do tempo $(69,6 \%$ ou 64 dias) (Quadro 1). Os sistemas extratropicais anticiclônicos e frontais aumentaram a frequência em relação ao inverno, 44,6\% e 25\%, respectivamente (Quadro 1), fazendo recuar os sistemas tropicais para latitudes mais baixas. De acordo com Tarifa (1975), o fluxo polar oscilante é o mais próximo do habitual na primavera e a quantidade de precipitação dependerá da continuidade ou do enfraquecimento do anticiclone polar.

Entre uma evolução da FPA e outra, os fluxos polares variaram de interrompido, oscilante e dominante, sendo que, no cômputo geral, os sistemas extratropicais controlaram a maior parte do tempo da primavera. Os fluxos interrompidos prevaleceram no início da primavera, quando ainda trazia consigo características do inverno, e, na segunda metade da primavera, os fluxos polares passaram a dominantes e oscilantes, com as passagens frontais mais rápidas impossibilitando a atuação dos sistemas tropicais (fluxo polar dominante) (Quadro 3). Conforme sugeriu Tarifa (1975), as combinações entre o fluxo oscilante e interrompido provocam totais pluviométricos ligeiramente acima do habitual, assim como as combinações de oscilante e dominante promovem totais pluviométricos inferiores ao habitual.

Não necessariamente um intervalo maior entre uma frente e outra signifique um fraco abastecimento de ar polar, visto que o processo de anticiclogênese da alta migratória polar pode ser fortalecido durante seu avanço para o trópico devido à circulação de altitude (subsidência na retaguarda dos cavados de altitude), bem como pela própria demora na tropicalização da alta polar (SPT), pois a disponibilidade de radiação solar ainda não é tão intensa quanto no verão.

$\mathrm{O}$ escoamento difluente e a dianteira dos cavados em altitudes favorecem o levantamento das parcelas de ar, contribuindo às instabilidades verificadas no período. A dinamização mais frequente das FPAs e o desenvolvimento de suas repercussões (R) foram auxiliados por este tipo de escoamento verificado em altitude. A frequência dos cavados de 500 $\mathrm{hPa}$ aumentou consideravelmente em detrimento dos anticiclones em relação ao inverno (Quadros 1 e 2).

\section{Verão 2008-2009}

Durante o verão, o mecanismo geral da circulação continua a seguir as mesmas bases das outras estações.

Não existe, na realidade, uma inversão da circulação. Considere-se também que, em grande parte, as condições diferentes de tempo que ora ocorrem, embora produzidas pelas mesmas massas de ar, decorrem das modificações que elas apresentam em suas propriedades de fonte e, sobretudo, pelas modificações impostas em seus deslocamentos sobre o continente, agora bem mais aquecido (MONTEIRO, 1968, p.141). 
Nesta estação, os sistemas tropicais atuaram durante $50 \%$ do período, sendo que o STA foi o mais frequente (38,8\%), seguido pelo STAC (18,9\%). A atuação desses sistemas foi também influenciada pelo anticiclone em $500(58 \%)$ e $250 \mathrm{hPa}(51 \%)$ (designado atualmente por Alta da Bolívia), mas que, desde os trabalhos de Serra (1954), Serra e Ratisbona (1942) e Strang (1986), já foi descrito com precisão quanto à sua posição e influência
(Quadros 1 e 2; Figura 3). Nos casos de superposição desses anticiclones, desde a superfície até $250 \mathrm{hPa}$, o tipo de tempo predominante foi anticiclônico quente e seco (devido à subsidência de ar superior), quase sem nuvens e com vento calmo. Nos topos da Serra do Mar, foram registradas, nestes casos, temperaturas bastante elevadas, superiores a $30^{\circ} \mathrm{C}$, e temperaturas de ponto de orvalho em torno de $11^{\circ} \mathrm{C}$.

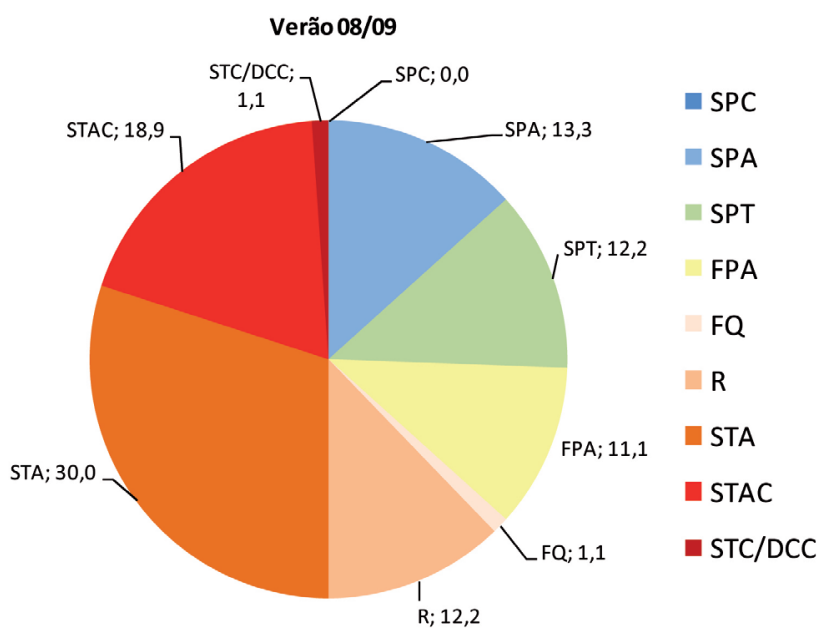

Figura 3: Frequência dos sistemas atmosféricos durante o verão de 2008/2009, no nordeste do estado de São Paulo. Org.: Gustavo Armani, verão, 2010.

A participação das FPAs e suas repercussões (R) foram equivalentes à da primavera $(11,1 \% \mathrm{e}$ $12,2 \%$, respectivamente), mas diminuíram progressivamente de janeiro para março (Quadro 2). Já os avanços dos anticiclones migratórios polares diminuíram nesta estação, com o SPA atuando por apenas 13,3\% do período (Quadros 1 e 2). Além da diminuição na frequência do SPA, deve-se considerar que

[...] a massa polar, após o solstício de verão, além do enfraquecimento do abastecimento de ar polar, atravessa o continente em processo de aquecimento mais intenso, o que implica em que suas propriedades sejam consideravelmente diferentes daquelas observadas no decorrer do inverno (MONTEIRO, 1973, p. 42).

Pela análise de espessura (superfície a 500 $\mathrm{hPa}$ ), há de considerar-se que as FPAs, no verão, manifestaram-se principalmente em altitude (cerca de $500 \mathrm{hPa}$ ), que o CPTEC (2009) designou como "frentes subtropicais". Apenas a última FPA de março agiu junto à superfície. Ocorreram, ao todo, 12 FPAs no verão (incluindo suas repercussões), com um intervalo médio entre elas de 5 dias. Os intervalos oscilaram de 0 dia entre uma frente e outra, quando, num mesmo dia de atuação, uma nova frente se somou àquela atuante, a 11 dias de intervalo (Quadro 3), sendo que os intervalos maiores foram os mais frequentes (maiores que 6 dias) (Quadro 3). A duração das FPAs, no verão, deu-se em geral dois ou três dias, decorrentes das repercussões pré e pós-frontais, que foram comuns nesta estação. Neste período, em fevereiro, ocorreu apenas uma vez o avanço de uma frente quente (FQ) (Quadros 1, 2 e 3).

A sucessão dos sistemas atmosféricos entre uma frente e outra seguiu o padrão clássico para o estado de São Paulo na primeira metade da estação. $\mathrm{Na}$ 
segunda metade do verão, as frentes ondularam sobre o estado de SP, recuando para sul da área de estudo, sendo substituída pelo STA ou STC (pouco frequente $1,1 \%$ ), não atuando nenhum sistema extratropical anticiclônico após a FPA (Quadros 1, 2 e 3).

As repercussões da FPA foram mais frequentes $(12,2 \%)$ que as próprias frentes $(11,1 \%)$, pois, muitas vezes, as FPAs ficaram estacionárias em latitudes ligeiramente mais altas ou mais baixas que a área de estudo, ou, muitas vezes, sobre o oceano, promovendo a repercussão sobre o N.E. do estado de SP.

Ao contrário da primavera, o STC e a DCC apresentaram baixa participação na área de estudo, respondendo por 1,1\% do período (Quadro 1). Segundo Monteiro (1968), no verão, as principais massas de ar que controlam o tempo são a Massa Tropical Atlântica e a Equatorial Continental, em conjunto com a Tropical Continental (pseudo e verdadeira). Entretanto, na área de estudo, as instabilidades e as esteiras de umidade contidas nas ZCAS (Zonas de Convergência do Atlântico Sul) e ZCU (Zonas de Convergência de Umidade) ocorreram dentro do STA, da FPA ou de suas repercussões (R). Com frequência, a ZCAS foi organizada pela FPA. Como a área de estudo está muito próxima do litoral e as FPAs tiveram uma trajetória mais oceânica que continental - o sistema principal atuante foi a FPA ou sua repercussão; e não a ZCAS.

A presença do anticiclone em 500 e $250 \mathrm{hPa}$ foi muito marcante nesta estação $(51,1 \% \mathrm{em} 250 \mathrm{hPa}$ e $58,9 \%$ em $500 \mathrm{hPa}$ ), fato típico para aquele período do ano, quando, em superfície, sobre o centro do continente, reinam as baixas pressões; e, em altitude, as altas pressões. Este anticiclone de $250 \mathrm{hPa}$, designado de Alta da Bolívia, juntamente, com a formação de um vórtice ciclônico de altos níveis sobre o N.E. do Brasil condicionam e mantêm a convergência de umidade em baixos níveis, favorecendo à formação e manutenção da ZCAS.

Nesta estação, os sistemas extratropicais aumentaram a participação para $50 \%$ do período, ficando os tropicais com a outra metade do período. Essa situação de equilíbrio de forças entre os sistemas extratropicais e os tropicais caracteriza essa estação, com um predominante tipo de fluxo polar interrompido. Entretanto, no início do verão, os fluxos polares foram mais intensos, então, predominando os tipos oscilante e dominante (Quadro 3), sendo que, na metade da estação, predominaram o interrompido e, no final, o tipo nulo (Quadro 3). Dessa forma, resulta que a fase inicial do verão foi mais controlada por sistemas extratropicais (principalmente as frentes e suas repercussões), sendo rapidamente substituída por outros sistemas extratropicais. No final da estação, a Alta Subtropical do Atlântico Sul controlou grande parte do tempo, bloqueando os avanços dos sistemas extratropicais. O padrão de bloqueio foi sustentado por uma crista de um anticiclone $(250 \mathrm{hPa})$ se estendendo para a região do Prata na retaguarda de um cavado em altitude.

\section{Outono 2009}

Assim como a primavera, o outono se caracteriza como uma situação de transição da circulação atmosférica no sudeste do Brasil - do período mais chuvoso para o período menos chuvoso. Nesta estação, os sistemas extratropicais controlaram $81,3 \%$ do tempo (74 dias), sendo que, desses, os anticiclônicos foram mais frequentes que os frontais, $59 \%$ e $22 \%$, respectivamente (Quadros 1 e 2). Como consequência, houve uma redução na participação dos sistemas tropicais (18,7\% ou 17 dias) (Quadros 1 e 2). Nesta estação, é comum a ocorrência dos veranicos no estado de SP decorrente dos sistemas anticiclônicos tropicais, mas, neste ano, eles foram pouco representativos, tendo ocorrido principalmente em maio, representado pelo aumento na frequência do STA (Quadro 2). Mesmo assim, foram muito breves. Este padrão de circulação está fora do habitual, principalmente em abril e junho, para o N.E. do estado de São Paulo, conforme descreveu Monteiro (1968), aproximando-se mais de uma circulação dos outonos de anos chuvosos, tal como ilustrado por Monteiro (1973). O fenômeno La Niña estava em sua fase madura, com intensidade moderada a fraca e deve ter influenciado a maior atividade da anticiclogênese polar.

Entre os sistemas anticiclônicos extratropicais se notou o aumento considerável do SPC para 7,7\% (ou 7 dias) de atuação na área em relação às outras estações (inverno, primavera e verão), principalmente no mês de junho, cujo potencial isobárico, no centro do anticiclone migratório, oscilou em torno de 1026 
hPa. Nas estações anteriores, este sistema não ultrapassou a $1,1 \%$ de frequência. A atuação desse sistema produziu resfriamentos fortes associados a um menor valor de umidade relativa do ar. O SPA, também, teve sua frequência elevada em relação às outras estações para $27,5 \%$ e o SPT para $24,2 \%$ (25 e 22 dias, respectivamente) (Quadros 1 e 2, Figura 4).

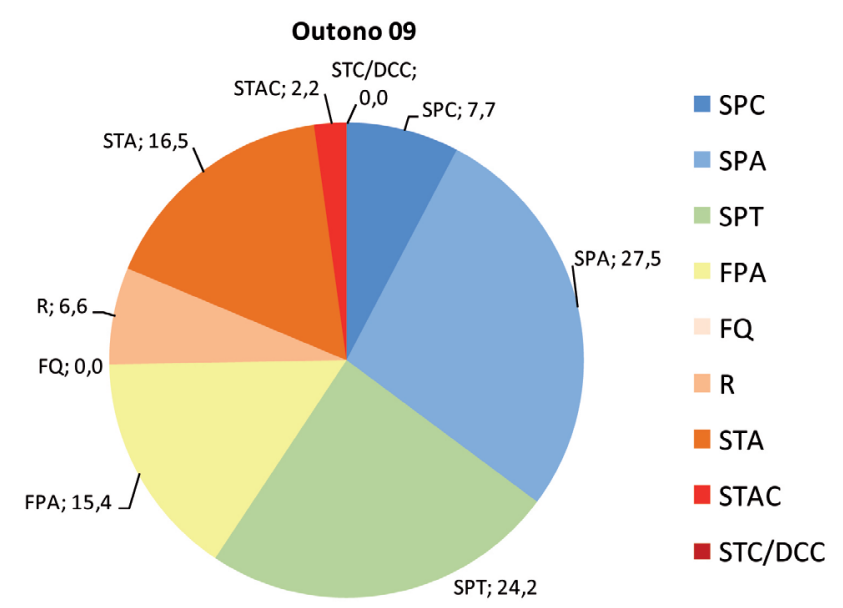

Figura 4: Frequência dos sistemas atmosféricos durante o outono de 2009, no nordeste do estado de São Paulo. Org.: Gustavo Armani, verão, 2010.

No outono, ocorreram 13 passagens frontais, com um intervalo médio entre elas de 5,4 dias. Foi a estação, no período analisado (inverno 2008/outono 2009), com maior número de avanços frontais, seguida do verão (12 passagens frontais). Diferentemente do verão, as FPAs, nesta estação, manifestaram-se da superfície até $500 \mathrm{hPa}$. Os intervalos entre as frentes foram em geral mais curtos, de 4 a 5 dias, sendo que o menor intervalo foi de dois dias, e o maior 14. A duração das frentes sobre a área de estudo mais comum ou frequente foi de 2 dias, seguido por 1 dia e 3 dias. Houve também três casos em que a frente passou muito rapidamente sobre a área de estudo, sendo logo precedida pela alta migratória, dessa maneira, não produzindo ou controlando o tempo. Nestes casos, a duração da FPA foi de 0 dia (Quadro 3). Diferente do habitual para esta estação, quando a circulação se assemelha mais com a do verão (MONTEIRO, 1968), as FPAs tiveram uma maior frequência no início da estação, com uma ligeira redução no final dela (Quadro 2).

Com a manifestação da FPA nos níveis mais altos da atmosfera, detectou-se o aumento na frequên- cia dos cavados em 500 e $250 \mathrm{hPa}$, com a consequente redução da atuação dos anticiclones. Isso marca o deslocamento da área de maior baroclínia para latitudes mais baixas nesta época do ano, associado ao aumento da frequência do JST sobre a área (Quadros 1 e 2).

Em função da frequência elevada dos sistemas polares e do alto valor isobárico do anticiclone migratório polar, o fluxo polar, no outono, foi classificado como dominante, e, dos 14 avanços polares do outono, 10 foram do tipo Dominante e quatro do tipo Interrompido. No primeiro terço do outono, não ocorreu nenhuma atuação dos sistemas tropicais.

\section{CONCLUSÕES E CONSIDERAÇÕES FINAIS}

Sobre os resultados de frequência dos sistemas atmosféricos, no ano compreendido pelo inverno de 2008 ao outono de 2009 , destaca-se que ocorreram 45 passagens frontais com duração mais frequente (dias de atuação) de um dia, controlando $21,9 \%$ do ano. Os intervalos entre uma frente e outra mais frequentes foram de 5 a 6 dias, oscilando entre um mínimo de 0 (com duas frentes num mesmo dia) a 18 dias. Neste 
ano em análise, houve apenas uma ocorrência de uma FQ ( $0,3 \%$ do ano) e as repercussões da FPA (R) foram de importância ao controle do tempo ao longo do período focalizado (8,5\%) (Quadros 1 e 2).

Os sistemas extratropicais (anticiclônicos e frontais) controlaram a maior parte do tempo $(64,9 \%$ do ano), sendo que os anticiclônicos atuaram durante $43 \%$ do ano; e os frontais, $21,9 \%$. O restante do tempo foi dominado pelos sistemas tropicais (Atlântico e Continetal) (35,1\%), sendo que, desses, os sistemas Atlânticos atuaram por 31,8\% e os Continentais 3,3\%. Este fato é esperado, pois o N.E. do estado de São Paulo está muito próximo do oceano, sendo mais facilmente controlado pelos sistemas Atlânticos que pelos Continentais (Quadros 1 e 2).

Referente aos fluxos polares neste período em análise, como um todo, poder-se-ia inferir que predominaram o tipo oscilante (com uma tendência para interrompido) devido à elevada frequência dos sistemas extratropicais (64,9\%) (Quadros 1 e 2), sendo um ano diferente do habitual para este trecho do estado, cujos sistemas tropicais apresentam equivalência no domínio do tempo com os extratropicais (50\% para os tropicais e 50\% para os extratropicais) (MONTEIRO, 1973).

Tarifa (2002), realizando a análise sinótica para os anos 1984, 1985 e 1986, não encontrou nenhuma situação característica da RFPA que pudesse ser digna de nota; se eventualmente ocorreu alguma vez, ela foi agrupada como R (repercussão da FPA). Neste trabalho, no período analisado (inverno de 2008 ao outono de 2009), não se registrou a ocorrência da RFPA. Tal fato pode estar relacionado ao aprimoramento das técnicas disponíveis atualmente para a análise sinótica, como imagens de satélites e supercomputadores para modelagem e traçado de cartas sinóticas de altitude e superfície. Pelo que se pôde perceber neste um ano de análises sinóticas diárias, a RFPA está muito relacionada ao que hoje de designa por ZCAS, bem como pela atuação da massa Equatorial continental $(\mathrm{mEc})$. As descrições dos tipos de tempo que a mEc é praticamente a mesma daquela que se observa hoje em campo quando da atuação da ZCAS. No entanto, acredita-se que este assunto mereça um estudo detalhado para a atualização e adequação da linguagem e terminologia dos trabalhos de Serra e Ratisbona (1942) e Monteiro $(1968,1973)$.

Das análises sinóticas e do ritmo dos sistemas atmosféricos, percebe-se que a geografia tem muito a ganhar com as análises da circulação de altitude, porque alguns fatos são decorrentes de processos de escalas superiores. Essas análises ganham consistência para compreender a expressão geográfica do clima, as relações de causalidade entre a circulação atmosférica e a variação temporal dos atributos, mas, principalmente, porque propicia ao geógrafo compreender a situação de um pequeno espaço numa dimensão global/zonal. Compreende-se, por exemplo, as relações da Alta da Bolívia com a dinamização das baixas continentais, dos temporais no sudeste do Brasil; do suporte dinâmico das correntes de jato e a evolução da frente polar, produzindo frentes de avanço rápido ou lento. Percebem-se as interações entre os fluxos polares na dinamização das baixas continentais e a intensificação dos processos convectivos, onde tudo está conectado nos diversos ritmos (diários, mensais, sazonais).

A análise da sequência de cartas sinóticas, vislumbrando a gênese, trajetória e movimentação e ocaso de sistemas atmosféricos, permite a compreensão do ritmo de sucessão habitual dos sistemas atmosféricos, "que se expressam na paisagem, mais pela visão concreta dos seus efeitos nos outros fatos das grandes massas (vegetação, drenagem, etc.) do que pela permanentemente agitada atmosfera que a envolve" (MONTEIRO, 1963, p.172). Desta forma, a análise sinótica em sequência se constitui em um meio que visa ao fim sintético da compreensão (MONTEIRO, 1963). Aduz o autor que, somente com este tipo de análise, as expressões quantitativas terão significação quando subordinadas à concepção qualitativa (MONTEIRO, 1963).

\section{REFERÊNCIAS}

ARMANI, G. Interações entre a atmosfera e a superficie terrestre: variações da temperatura e umidade na bacia B do Núcleo Cunha (IF) - SP. 2004. 198f . Dissertação (Mestrado em Geografia Física) - Faculdade de Filosofia, Letras e Ciências Humanas, Universidade de São Paulo. São Paulo, 2004. 
Análise topo e microclimática tridimensional em uma microbacia hidrográfica de clima tropical úmido de altitude. 2009. 272f. Tese (Doutorado em Geografia Física) - Faculdade de Filosofia, Letras e Ciências Humanas, Universidade de São Paulo. São Paulo, 2009. 2v.

AZEVEDO, T. R. Derivação antrópica do clima na Região Metropolitana de São Paulo abordada como função do ritmo semanal das atividades humanas. 2001. 434f. Tese (Doutorado em Geografia Física) Faculdade de Filosofia, Letras e Ciências Humanas, Universidade de São Paulo. São Paulo, 2001.

BOIN, M. N.; ZAVATTINI, J. A. Variações do Ritmo Pluvial no Oeste Paulista: gênese e impactos erosivos. Geografia, v. 30, p. 115-139, 2005.

CONTI, J. B. Circulação secundária e efeito orográfico na gênese das chuvas na região lesnordeste paulista. São Paulo: Instituto de Geografia da Universidade de São Paulo, 1975 (Série Teses e Monografias, 18).

HAMILTON, M. G.; TARIFA, J. R. Synoptic aspects of a polar outbreak leading to frost in tropical Brazil, july 1972. Montlhy Weather Review, v. 106, p. 15451556. 1978.

JARDIM, C. H. Os microclimas e o uso do solo no vale do rio Aricanduva. In: TARIFA, J. R.; AZEVEDO, T. R. (org). Os climas na cidade de São Paulo: teoria e prática. São Paulo: GEOUSP, 2001. p.188-199 (Coleção Novos Caminhos, 4).

KOUSKY, V. E.; ELIAS, M. Meteorologia Sinótica: parte I. São José dos Campos: INPE, 1982.

MONTEIRO, C. A. de F. Sobre a análise geográfica de seqüências de cartas de tempo. Revista Geográfica, n.58, p. 169-179, 1963.

O clima da Região Sul. In: GEOGRAFIA Regional do Brasil: Grande Região Sul. Rio de Janeiro: IBGE/Conselho Nacional de Geografia, 1968. v.4. p. 117-169.
- A frente polar atlântica e as chuvas de inverno na fachada sul-oriental do Brasil. São Paulo: Instituto de Geografia da Universidade de São Paulo, 1969 (Série Teses e Monografias, 1).

. Análise rítmica em climatologia: problemas de atualidade climática em São Paulo e achegas para um programa de trabalho. São Paulo: Instituto de Geografia da Universidade de São Paulo, 1971 (Climatologia, 1).

. A dinâmica climática e as chuvas no estado de São Paulo: estudo geográfico sob a forma de atlas. São Paulo: Instituto de Geografia da Universidade de São Paulo, 1973.

MONTEIRO, C. A. de F.; MARKUS, E.; MARKHAN, C. Comparação da pluviosidade nos Estados de São Paulo e Rio Grande do Sul nos invernos de 1957 e 1963. São Paulo: Instituto de Geografia USP, 1971 (Climatologia, 3).

MONTEIRO, C. A. de F.; TARIFA, J. R. Contribuição ao estudo do clima de Marabá: uma abordagem do campo subsidiária ao planejamento urbano. São Paulo: Instituto de Geografia USP, 1977 (Climatologia, 7).

SANT'ANNA NETO, J. L. Ritmo climático e a gênese das chuvas na zona costeira paulista. 1990. 156f Dissertação (Mestrado em Geografia Física) - Faculdade de Filosofia, Letras e Ciências Humanas, Universidade de São Paulo. São Paulo, 1990.

SERRA, A. Circulação Superior. Revista Brasileira de Geografia, v.4, n.1, p. 1-126, 1954.

SERRA, A.; RATISBONA, L. As massas de ar na América do Sul. Rio de Janeiro: Ministério da Agricultura/Serviço de Meteorologia, 1942.

SETTE, D. M. O clima urbano de Rondonópolis. 1996. 242f. Dissertação (Mestrado em Geografia Física) - Faculdade de Filosofia, Letras e Ciências Humanas, Universidade de São Paulo. São Paulo, 1996. $2 \mathrm{v}$. 
SETTE, D. M. O holorritmo e as interações trópico-extratópico na gênese do clima e as paisagens do Mato Grosso. 2000. 394f. Tese (Doutorado em Geografia Física) - Faculdade de Filosofia, Letras e Ciências Humanas, Universidade de São Paulo. São Paulo, 2000.

STRANG, D. M. G. D. Pequeno altas climático do ar superior para a América do Sul. Relatório Técnico ECA-03/86. São José dos Campos: Ministério da Aeronáutica, 1986.

TARIFA, J. R. Sucessão de tipos de tempo e variação do balanço hídrico no extremo Oeste paulista. São Paulo: Instituto de Geografia da Universidade de São Paulo, 1973 (Série Teses e Monografias, 8).

Fluxos polares e as chuvas de primavera-verão no Estado de São Paulo: uma análise quantitativa no processo genético. São Paulo: Instituto de Geografia da Universidade de São Paulo, 1975 (Série Teses e Monografias, 19).
. Análise topo e microclimática e o trabalho de campo: o caso de São José dos Campos. São Paulo: Instituto de Geografia USP, 1981 (Climatologia, 11).

. Os climas nos maciços litorâneos da Jureia-Itains: um ensaio de ritmanálise. 2002. 477f. Tese (Livre-docência em Geografia Física) - Faculdade de Filosofia, Letras e Ciências Humanas, Universidade de São Paulo. São Paulo, 2002. 2v.

TARIFA, J. R.; MONTEIRO, C. A. de F. Balanço de energia em sequência de tipos de tempo: uma avaliação do oeste paulista (Presidente Prudente) 1968-1969. São Paulo: Instituto de Geografia USP, 1972 (Climatologia, 5).

ZAVATTINI, J. A. Dinâmica Climática no Mato Grosso do Sul. Geografia, Rio Claro, v. 17, n. 2, p. 69-95, 1992. 